\title{
The Status and Role of Competency Model in Enterprise Human Re- source Management
}

\author{
Xiaoyu Lei* \\ Shaanxi Coalbed Methane Development Co., Ltd., Xi'an, Shaanxi, 713500, China
}

\begin{tabular}{ll}
\hline ARTICLE INFO & ABSTRACT \\
$\begin{array}{l}\text { Article history } \\
\text { Received: } 10 \text { June } 2020\end{array}$ & $\begin{array}{l}\text { The competency model is a widely-used human resource management } \\
\text { tool that can be applied to human resource management in different } \\
\text { regions, different fields, different enterprises, and positions of different } \\
\text { Revised: } 17 \text { June } 2020\end{array}$ \\
$\begin{array}{l}\text { Accepted: } 9 \text { October } 2020 \\
\text { fairness of enterprise human resource management, give full play to the } \\
\text { promotion of human resource management to the development of enter- } \\
\text { published Online: } 16 \text { October } 2020\end{array}$ & $\begin{array}{l}\text { ment goals. } \\
\text { Keywords: }\end{array}$ \\
Competency model & \\
Enterprise & \\
Human resource management & \\
Status & \\
Role &
\end{tabular}

\section{Introduction}

$\mathrm{I}$ $\mathrm{n}$ the process of human resource management of an enterprise, if the competence model is divided according to different standards such as business processes, roles, and positions within the enterprise, synthesizing these standards together to describe the competency model with different employee characteristics, and use it as a specific standard to measure the work behavior of employees in a certain position, thus forming a competency model. Nowadays, with the rapid development of the socialist market economy, the market competition is becoming fiercer, if an enterprise wants to achieve its own healthy and sustainable development, it must focus on managing the internal human resource of the enterprise, comprehensively measure the working status, work efficiency and work results of employees, and weigh the comprehensive capabilities of employees, and use it as an important information for employee promotion and development, in order to stimulate the work enthusiasm of employees, urge employees to consciously and actively comply with the regulations of the enterprise's positions, realize the management of human resource, and lay the foundation for the healthy development of the enterprise.

\section{The Status of Competency Model in Enter- prise Human Resource Management}

Compared with the traditional analysis of employee competence and quality, in the process of constructing competency model, "people" should be taken as the core content, and attentions should be paid to the details of the work

\footnotetext{
*Corresponding Author:

Xiaoyu Lei,

male, Han Nationality, a native of Pucheng County, senior economist title;

Research direction: human resource management;

E-mail:274479903@qq.com.
} 
completed by the employees in the process of work, and pay attention to the way in which the employees achieve their work goals and how to complete the work goals, so as to reflect the ability and quality of employees, it is used as an important guidance material in enterprise recruitment, employee training and performance management.

Competency model is an important development tool in human resource management of enterprises, which is paid special attention by enterprise managers and human resource managers. With the rapid development of knowledge economy in modern society, more and more knowledge talents appear in enterprises, the original employee analysis has been unable to meet the enterprise's employee management needs. At this time, the competency model is used by the enterprise in human resource management, becoming an important means of human resource management strategy. For enterprise organizations, the application of competency model can strengthen the connection between individuals' visions of enterprise organizations, enterprise strategic development and market opportunities; for enterprise managers, the competency model provides important information for carrying out human resource management and mastering the overall situation of enterprise employees; for employees, the ability organization model can provide them with clear work standards, guide employees "what needs to be done", and provide guidance for employees' independent development and growth ${ }^{[1]}$.

In enterprise human resource management, the competency model can be reflected in various forms, providing a unified standard and overall framework for enterprise managers, human resource management staff, and post employees, it can be used by enterprises as an important means to improve competitive advantage and performance management, an effective communication tool, and an effective way to integrate human resource.

\section{The Role of Competency Model in Enter- prise Human Resource Management}

Firstly, it can standardize employee training. In the process of enterprise human resource management, the enterprise uses the competency model to conduct an all-round evaluation and assessment of employees, so as to find out the shortcomings of employees' work advantages and capabilities, and use it as the basis for the training plan, find the key points for employee training, formulate a scientific and reasonable employee training plan, and improve the working ability and comprehensive literacy of employees in a purposeful and planned manner. The main purpose of training for employees is to enable them to master the basic knowledge, skills and other abilities required in the job; in this process, we can give full play to the role of the competence model, to the greatest extent, ensure that the skills obtained by employees participating in training can be applied to the actual work process ${ }^{[2]}$.

Secondly, it helps to optimize the allocation of employee resource within the enterprise. Staffing is an important part of enterprise human resource management. Different job positions have different requirements for employees' comprehensive capabilities and professional skills. Using the competency model, we can accurately analyze the qualities and abilities of employees, in order to match employees with more suitable job positions, give full play to the advantages of corporate employees, realize the optimal allocation of internal human resource, and improve the overall management capabilities of the enterprise.

Thirdly, it helps to carry out corporate talent selection and recruitment activities and improve the efficiency of talent recruitment. In enterprise management, the higher the personal quality of employees than the actual needs of job jobs, the more likely it is to create more work value. Therefore, enterprises can use the competency model as an important tool for selecting and recruiting talents, and analyze and evaluate the abilities of job applicants, so as to ensure that the qualities and abilities of the talents employed are far higher than the job requirements, creating more value for the enterprise; at the same time, the ability and quality requirements of specific positions can also be used as the basic standard for talent selection, so as to achieve the selection and classification of talents, prompt enterprises to accurately locate talents and positions, achieve the goal of "directional recruitment", and improve the efficiency of human resource management .

Finally, it helps to improve performance management and optimize salary management. From the perspective of the competency model, the enterprise carries out performance management and salary management, which is mainly based on the process of employees' completion of business goals, and integrates the enterprise's organizational vision, development needs, and organizational expectations into employees' personal work behaviors, as a standard for assessing employees' performance evaluation results, and laying a scientific management foundation. For some more complex jobs, the enterprise using a single KPI system have been unable to fully measure the work behavior and value of employees, at this time, we can use the competency model and specific competence indicators to compare and analyze the advantages and disadvantages of employees to calculate the performance evaluation rewards or punishment of employees, so as to promote the working process of employees to be closely connected with their job growth, bonus floating, welfare treatment, career promotion, etc. 


\section{How to Give Full Play to the Role of Com- petency Model in Human Resource Manage- ment}

\subsection{Combining the Enterprise's Development Goals, Put Forward the Ability and Quality of Employees}

In order to give full play to the role of the competency model in enterprise human resource management, in the process of constructing the competency model, it is necessary to combine the actual situation of the enterprise and consider the current situation, development needs and development goals of the enterprise, respectively, by clarifying the development goals of the enterprise, and elaborating the work goals of employees in different departments and positions, this is used as the purpose of employees' work and as a standard for improving the ability and quality of employees. Staff should combine the business department, technical department, sales department, logistics department and other departments of the enterprise, consider their position and development needs in the process of human resource management, and propose the qualities that employees in different departments need to have, for example, employees in the business department need to have good communication and sales capabilities, be able to coordinate the relationship between customers and the enterprise, etc. ${ }^{[3]}$.

\subsection{Formulate Specific Performance Appraisal Standards and Weigh Employees' Comprehensive Capabilities}

In order to give full play to the role of the competency model in enterprise human resource management, specific and clear performance evaluation indicators must also be proposed, and the employee quality standards in the competency model should be quantified into specific evaluation items to measure the comprehensive capabilities and qualities of the employees. In this process, we can propose a reservation goal for the job, and then measure and analyze the employee's various work performance, judge the situation of completing the job goal, analyze and inspect its work process, so as to restrain and motivate employees, encourage employees to actively follow the rules of the enterprise, and realize the independent development and growth of employees ${ }^{[4]}$.

\subsection{Collect Data Extensively and Lay the Founda- tion for Model Building}

In order to give full play to the role of competency model in enterprise human resource management, we must recognize the importance of data. in the process of constructing the competency model and using the model, to convince employees of the model is to obtain the support of the employees and encourage them to realize the fairness and objectivity of the model. Based on this, we can understand employees' perception and experience of positions through questionnaire surveys and informal communication, and optimize and integrate questionnaire data, and use it to obtain reference data and use it as the basis for model building to form a model that "returns to the public", improve the credibility of the model, and give full play to the role of the model ${ }^{[5]}$.

\subsection{Flexible Use Competence Models to Promote the Healthy Development of Enterprises}

In order to give full play to the role of the competency model in enterprise human resource management, it is necessary to use this model flexibly and apply it to all aspects of enterprise human resource management., for example: recruitment of new employees, employee training, employee performance appraisal. In the recruitment process of new employees, we must first grasp the applicant's application purpose, understand its target position and target salary needs, and then conduct investigation and communication with the applicant according to the ability and quality standards in the competence model of different positions, and analyze the knowledge literacy, professional skill level, job ethics and sense of responsibility of employees, make a rough judgment on them, obtain more accurate judgment results, and use it as an important basis for hiring staff ${ }^{[6]}$.

In the training process of enterprise employees, according to the competence model corresponding to different departments and positions, the standards required by the model for the ability and quality of employees can be extracted. These standards are used as the main materials for formulating training plans, and ability and quality are used as the basic dimension. Specific training activities are carried out from each dimension to promote employees to improve and develop a certain ability through participating in training activities. For performance appraisal work, enterprises can correspond and analyze the various indicators of employees according to the competence model, which finally reflects whether employees can provide assistance to the progress and development of the enterprise, and whether the presence of employees hinders the construction of corporate culture, internal management, etc., so as to do rewards and punishments for performance evaluation and achieve efficient human resource management $^{[7]}$. 


\section{Thoughts on the Application of Compe- tence Model in Human Resource Manage- ment of Enterprises}

For enterprise human resource management, the competency model is a good management tool, but it will inevitably encounter some problems in the process of use. After all, this is just a model and cannot be completely covered by every individual employee. Therefore, when using this model in enterprise human resource management, it should be noted that this model is by no means static, however, it needs to be constantly adjusted and adjusted according to different enterprise development needs, different department work scopes, different job responsibilities and obligations, and different business processes; a good competence model needs to be able to promote the enterprise's employee recruitment, employee performance assessment management, employee training and its development ${ }^{[8]}$.

In the process of enterprise human resource management, in order to build a good competence model suitable for the development of the enterprise, it is necessary to fully mobilize the human, material and financial resources of the enterprise and invest a lot of time to think from multiple angles of enterprise managers, enterprise human resources managers, ordinary employees of the enterprise, and enterprise development, and in the process of practice, it continuously finds hidden problems and constantly corrects them, so as to improve the overall level of the competence model, which plays a role in promoting the development of the enterprise.

\section{Conclusion}

In summary, to apply the competency model to human resource management, enterprises must adhere to the principle of "seeking truth from facts" and establish a model that can meet their own development needs according to their actual situation, only in this way can the enterprise truly play the role of the competency model, become stronger from the root, and improve the core competitiveness of the enterprise. In the process of the construction and application of the competency model, the enterprise should combine the development goals, put forward the employee qualities needed for the development of the enterprise, and formulate detailed and specific performance evaluation standards, which will be used as a measure of the employee's competency. In addition, enterprises must flexibly use the competency model to apply it to recruitment, employee training and performance appraisal and other links to give full play to their role and provide assistance for the healthy development of the enterprise.

\section{References}

[1] Guo Cunhong. The status and role of quality model in human resources management of enterprises [J]. Times of Fortune, 2020(02):38-39.

[2] Wang Jiajia. The status and role of competency model in human resource management of enterprises[J]. Human Resources, 2019(12):23.

[3] Chen Yanping. Application of competency model in enterprise human resource management[J]. Market Modernization Magazine, 2017(09):110-111.

[4] Wang Wenbao. On the basic application of competency model in enterprise human resource management. Managing Director, 2010(02):181-182.

[5] Chen Jun. Competency Model J. Glamour China, 2010(35):16-16.

[6] Wu Zhaojun. Establish the human resource management system with competency model as the core $\mathrm{J}$. China training, 2005(01):23-24.

[7] Wan hungwai. To explore the application of competency model in the e -- HR system. Journal of Guizhou University, Social Sciences, 2005(03):105-109.

[8] Yang Zhixin. The application of competency model in enterprise human resource management. Intelligence, 2015(003):344. 